\title{
Democracia y liberalismo. De la Modernidad a la Postmodernidad. El problema de su conciliación
}

\author{
BERNARDINO BRAVO LIRA \\ UNIVERSIDAD DE CHILE
}

Resumen: La caída de la Unión Soviética no fue tan solo el final de una superpotencia: fue el fin del intento más consecuente de rehacer el mundo de acuerdo a los dictados de la razón humana. En la Postmodernindad importa más decir las cosas bien, en términos comprensibles, que decir cosas importantes. Se pasan a imágenes desde los textos impresos. Algunas de estas reflexiones son descritas en el presente trabajo para contestar y analizar que ha sido de la Democracia en esta nueva era, pasando por una revisión de la Democracia en distintos tiempos para culminar en un análisis de lo actual.

Palabras Claves: Democracia, Postmodernindad, Libertad, Seguridad, Liberalismo

\begin{abstract}
The fall of the Soviet Union was not just the end of a superpower; was the end of the more consistent attempt to remade the world according to the human reason`s dictum, in the Postmodernity it is more important to say the things right, in more understandable terms, rather than say important things. It is change to the images from printed texts. Some of these thinking are described in the present paper to answer and analyze what have been of Democracy in this new era, reviewing Democracy in different eras to end into an analysis of the actual.
\end{abstract}

Keywords: Democracy, Postmodernity, Liberty, Security, Liberalism

Nadie elige la época en la cual le toca vivir. Los alemanes se adelantaron a poner nombre a la nuestra. Hablan del Wende, es decir, del "gran vuelco". Siempre los hombres encuentran grandes los cambios que a ellos les toca vivir. Pero en este caso no parece exagerado. Se trata del fin de una época, el derrumbe de la Unión Soviética, y con el, de la partición de Berlín, de Europa y del mundo entre dos superpotencias. Es el, en rigor, el $W$ ende ${ }^{1}$. Estamos ante un cataclismo mental, un desmoronamiento en cadena de ideas y de ideales, al que no escapan las mentes de la Ilustración transmutados en inocentes metarelatos, al decir, de Lyotard ${ }^{2}$.

Con el Wende terminó, según indicios que muchos reconocen, la Modernidad racionalista. La caída de la Unión Soviética no fue tan solo el final de una superpotencia: fue el fin del intento más consecuente de rehacer el mundo de acuerdo a los dictados de la razón humana. Con ella murió el sueño ilustrado de un mundo mejor forjado por el hombre, en el que, al decir de Comte, los hombres

\footnotetext{
* Versión escrita de la ponencia presentada por el profesor Bravo en el II Congreso Estudiantil de Derecho y Teoría Constitucional.

${ }^{1}$ Czempiel, Ernst Otto, Weltpolitik im Umbruch. Das intrnationale System nach der Ende des Ost-West Konflikts, Munich 1991.

${ }^{2}$ Lyotard, Jean François, La Condición Postmoderne. Rapport sur le savoir,París 1979, trad. castellana Madrid 1984
} 
fueran mejores, más ricos y más felices. Esta ilusión terminó trágicamente. Por eso, nos encontramos en el umbral de una nueva época, la Postmodernidad, en cierto modo desilusionada, y al mismo tiempo aleccionada por este hundimiento ${ }^{3}$. En su pórtico podía leerse, como otrora en el templo de Delfos, la frase de Vattimo: nada es más absurdo que creer que el hombre, una minúscula partícula del universo, pueda cambiar algo de él. ${ }^{4}$

\section{De la cultura letrada a la de la imagen}

Con la Modernidad se acaba la cultura letrada. O sea, agoniza la escritura, el libro, los textos. Ustedes y yo somos la última generación educada con la palabra escrita, la letra impresa, desde el diario, y la revista hasta el libro. En la época moderna reinó la técnica para de reproducir lo que otros habían hecho. Vimos que llegó a su culminación, en la música, la escultura, la literatura y demás. Así por ejemplo, las obras de Händel se reproducen mejor de lo que se interpretaban en su tiempo. Igualmente pueden hacerse impresiones del Quijote -ahora que estamos en el año del aniversario- mejores que la edición Príncipe. Pero no se puede escribir de nuevo el Quijote, ni se puede componer otra vez la "Música del agua" de Händel.

Estas no son observaciones de mi cosecha. Tienen su antecedente en Spengler, quién descri-

${ }^{3}$ El término Postmodernidad es difícil de definir. Presenta al menos dos caras, una clara y otra difusa. Por un lado, importa descartar la Modernidad como algo de otra época, sin vigencia en los tiempos que vivimos. Tal es el sentido de la descalificacion de loa ismos, como metarrelatos. Por otro lado, el contenido de la Postmodernidad es eminentemente incierto. Nadie puede decir en que consiste. Es demasiado pronto para hacerlo. Estamos en los umbrales de ella y sus contornos no se han definido todavía. Tampoco en los albores de la Modernidad en el siglo xv podía anticiparse su contenido. Esto explica, en buena parte, la proliferación de obras sobre el tema. En ellas se disciernen tres directrices principales. Cada cual habla de fin de la Modernidad, según le va en ella. En Europa y los Estados Unidos, su epicentro, reina la decepción. Con el racionalismo se viene abajo toda su visión antropocéntrica del mundo. Unos buscan salvarla de algúnn modo y otros no ven más salida que un cosmocentrismo. Para Hispanoaménca, en cambio, este ocaso del racionalismo es reconfortante. Muchos no atinan sino a seguir, como siempre, las aguas de Europa, pero otros desde Sampay en 1942 hasta Steger en 1992, caen en la cuenta de que al desmoronarse la Modernidad ilustrada, el retraso de Hispanoamérica en asimilarla se ha convertido en ventaja suya. Por una renovación del antropocentrismo están en Europa quienes, como Martin Kriele, en vista del fracaso de la primera Ilustración, llaman a intentar otra, se supone que corregida y aumentada. Por un cosmocentrismo están quienes, como Lyotard, Derrida y Vattimo, ven en el fin de la Modernidad, el de la desmedida confianza en la razón humana, en una palabra, del antropocentrismo. Si el racionalismo proclamó la muerte de Dios, ahora proclaman la muerte del hombre, su disolucion en la naturaleza, próxima al budismo, a las doctrinas orientales. Por este camino Europa parece negarse a si misma y volver al punto de partida del pensamiento griego. Para Europa y 1os Estados Unidos, Lyotard, nota 2, intenta aunar tres corrientes derivadas de la Ilustración representadas por Saint-Simon, Nietzche y Marx. Kriele, Martin, Befrivg und politische Aufklaerung: Plaedoyer fuer die Wuerde des Menschen, Friburgo (Brisgovia) 1980. Braudillard, Jean; Rutschky, Michael; Sonnemann, UIrich y Hesse, Heidrun (comp.), Todder Moderne: Eine Diskussion, Tubinga 1983. Vattimo, Gianni, La fine della Modernita, Turin 1985, trad. castellana, Barcelona 1986. El mismo y otros, En torno a Postmodernidad, Barcelona 1990. Huyssen, Andreas y Scherpe, Klaus, Postmoderne. Zeichen eines kulturellen Wandels, Reinbek-Hamburgo 1986. Koslowski, Peter, Spaemann, Robert, Lew, Reinhard (eds.), Moderne oder Postmoderne Weinheim 1986. El mismo, Die Postmoderne Kultur, Munich 1988. Pico, José, (Comp.), Modernidad y Postmodernidad, Madrid 1988, con trabajos de diez autores, la mayoría estadounidenses. Ballesteros, Jesús, Postmodernidad, decadencia o resistencia, Madrid 1989. Casullo, Nicolás (comp.), El debate modernidad-postmodernidad, Buenos Aires 1989. Turaine, Alain, Critiqué de la Modernité, Paris 1992, trad. castellana Madrid 1994. Para Hispanoamérica, Sampay, Arturo Enrique, La crisis del Estado de derecho liberal-burgués, Buenos Aires 1942. Frankl, Viktor, Espíritu y camino de Hispanoamérica, Tomo I. La cultura hispanoaméricana y la filosofía europea, Bogotá 1953. Morandé, Pedro, Cultura y modernización en América Latina, Santiago 1984. El mismo, "Formacion del ethos barroco como núcleo de la identidad cultural iberoamericana", en Galli, Carlos y Schaiz, Luis, América Latina y la doctrina social de la Iglesia. Diálogo Latinoamérica-alemán, Buenos Aires 1992. El mismo, "Identidad cultural hispanoamericana", en M. 8 de octubre de 1995. Cousiño, Carlos, Die Verwaisung Lateinamerikas, Munich 1985. Follari, Roberto A., Modernidad y postmodernidad: una óptica desde América Latina, Buenos Aires 1990. Vásquez, José Agustín, "Morelos y Canudos. Dos episodios atípicos en la historia de Hispanoamérica", en Ciutlad los Césares 19, Santiago 1991. Bravo Lira, Bernardino, "America y la Modernidad: de la Modernidad barroca e ilustrada a la Postmodernidad”, en Jahrbuch fuer Geschichte von Staat, Wirtschuft and Gesellschaft Lateinamerikas, ColoniaWeimar-Viena 1993.

${ }^{4}$ Vattimo, nota 3. 
bió la decadencia señalando que: "Lo propio de ella es reproducir las obras maestras de otras épocas sin poder producir otras semejantes" ${ }^{\prime 5}$. Una observación similar la hace Altheim al tratar del ocaso del mundo antiguo. Entonces se recogieron y corrigieron los escritos clásicos, de los grandes escritores y pensadores griegos pero no se produjo nada semejante. Es una época de colecciones, repositorios y antologías. Vale la pena retenerlo.

Una cosa es la técnica que puede muy bien perfeccionarse en plena decadencia, y otra muy distinta el espíritu creador de los grandes maestros que solo se encuentra en épocas de esplendor.

Ha terminado la Modernidad, con todo lo grandioso que tuvo, y con el Wende ha empezado la Postmodernidad, que, en contraposición, podríamos caracterizar según señalamos antes, como una cultura de la imagen que también los es de la retórica. Importa más decir las cosas bien, en términos comprensibles, que decir cosas importantes. Se pasa de la imagen auditiva, con la radio, que fue primero fija y ahora es portátil y que tuvo primero como destinatario un auditorio abierto y ahora es personal. A esta imagen se añade la visual, con el cine y la televisión, y a esta la virtual con la computación. Entre las características propias de la cultura postmoderna está su apertura en contraste con la cultura oral, que es forzosamente presencial. Si en esta solo cabía comunicarse con personas que estaban físicamente al alcance de la voz, la cultura postmoderna, en cambio, parece no tener fronteras. Llega a un público masivo, pero sin capacidad intelectual de discernimiento. Basta un teléfono portátil o un computador para comunicarse directamente con Europa, sin cable interoceánico o lo que sea. Algunos hablan de globalización, pero es discutible hasta que punto ella va más allá del nivel técnico. Si difundir y repetir no es crear algo nuevo o más valioso. Las personas siguen siendo las mismas de antes, con sus afinidades y diferencias, aunque puedan verse y comunicarse entre sí, y se haya ampliado el horizonte de sus posibles relaciones.

Estamos en el umbral de una nueva época. Como es natural, todavía se manejan nociones, ideas, palabras, tópicos, provenientes de la que pasó, de una Modernidad teórica y teorizante y, sobre todo, constructivista. No faltan quienes tienen todavía con una mentalidad moderna piensan que para solucionar problemas y reorganizar el mundo hay que empezar por construir algún modelo. Inconscientemente creen poder reemplazar la política por la ingeniería política ${ }^{6}$. Eso fue lo propio de la Modernidad, sobre todo en su fase final totalitaria. El Wende de la Modernidad a la Posmodernidad nos obliga a revisar el tema. Con Jorge Manríque podemos preguntarnos ¿Qué fue de la democracia, qué fue del liberalismo, que fue de tanta invención? ¿Cómo trujeron? ${ }^{7}$.

\section{¿Que fue de esta de esta invención?}

No se trata de cábalas o suposiciones, sino de hechos, a veces brutales, pero por eso mismo, ineludibles ¿Qué ha pasado?. Para empezar podemos verificar que democracia y liberalismo están bastante venidos a menos, desgastados, como casas sin dueño, abandonadas de sus antiguos propietarios, más que ideales vivos, parecen ancianos esperando la muerte en casas de reposo. No sin amargura hacía ver la profesora Chantal Mouffe que en Europa y los países industriales hay un cierto rechazo de la democracia y el liberalismo. La verdad es que todo este andamiaje decimonónico parece hallarse en su cuenta regresiva. Pertenecen a una época anterior y no encuentran lugar en la actual. Cada vez tienen menos espacio vital y mental.

Lo mismo pasa en Hispanoamérica. Antonio Leal no ha vacilado en plantear que, a caso de

\footnotetext{
${ }^{5}$ Spengler, Oswald, Decadencia de Occidente, 2 vols, 1918-1922

${ }^{6}$ Hennis, Wilhelm "ubre die Krise der Politik in Neuzeik" en Merkur Munich 1971, trad. Castellana "Sobre la crisis de la política en la Edad Moderna" En: Humboldt, 48, Munich, 1972.

${ }^{7}$ Manrique, Jorge, Coplas a la muerte de su padre, múltiples ediciones, Santiago, 2008.
} 
la diferenciación de intereses en la población, su representación por los partidos se ha tornado imposible: "la gran interrogante de cómo el sistema de partidos y las instituciones corresponden al desafío de representación de una sociedad compleja, caracterizada por la multiplicidad y diferenciación de relaciones, donde ningún actor social es reconocible en una sola variable cultural, económica o de clase, como ocurrió en el pasado no lejano"8.

\section{De la democracia griega a la democracia leonina}

El tema da para mucho, aquí solo puedo trazar un par de pinceladas. Empecemos por la democracia. Este término griego combina krátos y demos, o sea, gobierno y pueblo. La palabra se refiere al gobierno del pueblo. Ahora bien, en la práctica, para los griegos el gobierno del pueblo era el gobierno de una escogida minoría dentro de la masa de habitantes de la ciudad. La democracia era eminentemente minoritaria y distinguida ${ }^{9}$. En esos términos, los ciudadanos tenían la posibilidad de intervenir, personalmente, en los asuntos públicos. Pero para que esto fuera factible, todo el resto de la población, desde luego miles de esclavos, periecos y otros habitantes de la ciudad tenían que trabajar a fin de asegurar a la minoría de ciudadanos el ocio creativo, ocio político, que les permitía participar en las asambleas. Esa fue, básicamente, la democracia griega.

Muchos que tienen por modelo de democracia a la griega, no reparan en que llegó a su apogeo bajo una dictadura, la de Pericles, cuando éste nombraba a los candidatos y los ciudadanos los elegían. La ignorancia al respecto llega a tal punto que en los Estados Unidos hay gente que está convencida que democracia y dictadura se oponen. Lo que les mueve a destruir dictaduras y en la vana esperanza de que sobre sus ruinas florezcan democracias. No les ha ido demasiado bien, porque las democracias ni surgen solas, ni se dejan imponer por la fuerza. En Hispanoamérica, en cambio, la práctica de nombrar a los candidatos por el gobierno y de sus elecciones por los ciudadanos se impuso desde muy temprano. Perdura desde Portales en el Chile de 1830 hasta el PRI ${ }^{10}$ del actual México. Este sistema hizo de México el único país políticamente estable del mundo hispánico, desde 1940 hasta nuestros días. Naturalmente no es igual a la democracia griega. En México vota mucho más gente, pero la selección de los candidatos por el gobierno es tanto o más estricta que en las flamantes democracias griegas.

Como para comer pescado, para comparar en historia, hay que tener mucho cuidado. Pero en este caso, Benjamín Constant se adelanta a hacer, contrapuso la democracia griega, que es el punto de referencia, ya que ellos inventaron la palabra y la institución, con la democracia moderna ${ }^{11}$. En principio, el ideal de la moderna es que participen todos los que puedan -ciegos, analfabetos, ausentes, minusválidos, mayores de edad y quienes no estén completamente dementes. En una palabra, en los votantes lo que importa es la cantidad y no la calidad. Esto es aún más fácil de conseguir, como echarle agua a la sopa. A mayor cantidad de electores, menor es el peso del voto individual, hasta el punto de que no pasa de ser una ficción, un acto ritual.

Un modo de organizar esta democracia masiva es la representación. Se llega así a la democracia representativa. Benjamin Constant señaló en el siglo pasado sus deficiencias, en comparación con la democracia griega. En Grecia observó, el ciudadano renunciaba a todo para recibir algo. O sea, para obtener una cuota de poder. De hecho, podía contentarse participando personalmente en la asamblea de los ciudadanos, el ágora, y gritar y patalear hasta hacerse oír de los demás. En cambio, dice el mis-

\footnotetext{
${ }^{8}$ Leal, Antonio, "Democracia y Partidos", en el Mercurio, 5 de enero de 1995. Bravo Lira, Bernardino "Fatiga de la superestructura partidista. Chile 1990-1995” en Ciudad de los Césares 42, Santiago, 1996.

${ }_{9}^{9}$ Por todos, Rodríguez Adrados, Francisco Choque de civilizaciones, Madrid, 2005.

${ }^{10}$ Krauze, Enrique, La Presidencia Imperial, México, 2002.

${ }^{11}$ Constant-Rebecque, Benjamin de, "La liberté des anciens comparée à celle des modernes", Discurso en el Athenée Royale, París 1819, ahora en el mismo Ecrits et discours politiques, París 1954
} 
mo Constant, "en la democracia moderna se renuncia a todo a cambio de nada ${ }^{12 "}$. Podría añadirse, que cada vez se obtiene menos, porque mientras más aumenta el número de los electores, de votantes o como se los llame, más se desvaloriza cada voto, hasta llegar a ser insignificante, despreciable, como un volantín. En lugar de sopesarse racionalmente las opiniones, se cae en el recuento numérico de votos, al igual que en una encuesta. ¿Qué poder efectivo tiene un votante entre cien mil, no digamos entre cien millones o más, como en Brasil, en Estados Unidos y en Rusia?.

La conclusión es dura, para el voto volantín es camino de servidumbre, pero en la democracia moderna se renuncia a todo, para someterse en todo a quienes salgan elegidos, aunque no sean los candidatos por los cuales uno votó o aunque ni siquiera se haya votado. Es un pactum subietionis. Se confunde democracia con electoralismo, el rito con la sujeción irrestricta al elegido. En este sentido, según Constant, comparada con la griega, la democracia moderna es un mal negocio. Como, además, es representativa, el que representa y representa se lleva la mejor parte. Es una democracia leonina. Genera una Nomenklatura y una Nowa Klasa que captura el poder y maneja a los ciudadanos ${ }^{13}$.

\section{Democracia totalitaria}

Este mal negocio culminó en el siglo XX de una manera de sobra conocida, en el Estado totalitario ${ }^{14}$. Con el murieron las últimas ilusiones: el cuento de las elecciones populares, de la democracia y de que todos serían libres porque votaban. Todo esto acabó en un grotesco metarelato, que nadie se toma en serio, como en los cuentos de hadas. Al decir de Borges en 1976: "Descreo de la democracia, ese curioso abuso de las estadísticas ${ }^{15 "}$.

La Nomenklatura vive del país, elije a los candidatos, maneja las elecciones y monopoliza el poder. Y por ese camino se llega a qué. Por ese camino se encumbra al totalitarismo ${ }^{16}$.

El mejor ejemplo es la Unión Soviética, donde la Nomenklatura se mantuvo firmemente anclada en el poder durante varias décadas. Wyschinski, embajador de Stalin en las Naciones Unidas, hizo su apología con las siguientes palabras "En nuestra democracia la Constitución no protege a los individuos contra el Estado, protege al Estado contra los individuos ${ }^{17 "}$. Esa es la democracia totalitaria, expuesta, sin ambages, ante un foro internacional. Esto se tuvo por una cosa aberrante, y así lo consideraron durante algún tiempo muchos, pero resulta que Estados Unidos llegaron, no hace mucho, a lo mismo. Bovard, un autor norteamericano, dice "Cuando fue la independencia de los Estados Unidos, no habia garantía mayor para las personas que la ley. A una persona no se le podia exigir nada que no estuviese impuesto por una ley. Hoy -dice él- la mayor amenaza contra el ciudadano es la ley. Porque mayorías ocasionales le imponen las obligaciones que sean $18 \prime$ ".

La democracia invirtió el sentido de la ley, en lugar de limitación frente al poder la convirtió

\footnotetext{
${ }^{12}$ Constant-Rebecque, nota 11.

${ }^{13}$ Djilas, Milovan, Nowa Klasa. Analiza systemu Kommunitzycznego, Nueva York 1956, trad. castellana, Barcelona, 1957. Voslensky, Michael, Nomenklatura, (1980), Barcelona 1981.

${ }^{14}$ Tocqueville, Alexis deL'Ancien Régime et la Révolution (1856), Madrid 2005.Arendt, Hanna, Orígenes del Totalitarismo (1951), repara en el papel de la elite dirigente. Voslensky, Michael, Nomenklatura, (1980), Barcelona 1981. Talmon, Jacob, The Origins of Totalitarian Democracy, Londres 1952, Seidel ,Rymo y Jenker, Siegfried, Wege des Totalitarismus-Forscbung, Darmstadt 1968, Schapiro, Leonard, El Totalitarismo (1972), trad. castellana México 1981 Bracher, Karl Dietrich, Zeit der Ideologien (1982) Buenos Aires 1989. Reinhard, Wolfgang: Geschichte der Staatsgewalt. Eine vergleichende Verfassungsgeschichte Europas von den Anfängen bis zur Gegenwart, Munich 1998. Traverso, Enzo, El totalitarismo. Historia de un debate, Buenos Aires, 2000 .

${ }^{15}$ Fernández Ferrer, Antonio, Borges A/Z selección, prólogo, notas, Madrid 1988.

${ }^{16}$ Ver nota 14.

${ }_{17}$ Wyschinski, Andrei, Cuestiones de teoría del Estado y del derecho (en ruso), Moscú 1949.

${ }^{18}$ Bovard, James, Lost Right. The destruction of the American Liberty. Nueva York 2000.El mismo, "Imperio de la Ley" en El Mercurio 14 de junio de 1994.
} 
en un instrumento de suyo en contra del ciudadano. Este travestismo es el trágico desenlace de la fantasmagoría de Rousseau, quién abogó por sustituir "el gobierno de las leyes en lugar del gobierno de los hombres $^{19 "}$. Pero las leyes las hacen los hombres, así que no podía ser de otro modo. Que en los Estados Unidos la democracia ha terminado por ser totalitaria, similar a la de la Unión Soviética, con la diferencia de ahora que es la única que queda, que se mantiene en pie, y que se considera relativamente segura. Tanto que tras la caída de las torres gemelas se permitió pasar por encima de todas las libertades y garantías.

En suma, la gran paradoja de la democracia moderna, no de la griega, es que constituye un espejismo, como tal inalcanzable. Prometer, a la manera de la Unión Soviética un mundo mejor y más feliz siempre es posible, pero para más adelante, para cuando triunfe el partido, para cuando alcance la mayoría, para cuando el mundo sea comunista.

Para la presente generación, según esto, la democracia se reduce a sacrificio y exigencia, en tanto que el soñado bienestar será para la otra generación. Entretanto, mientras la Nomenclatura disfruta del presente, argumentando que prepara el futuro, el sufrido pueblo está a merced de los sacrificios exigidos por ella. Pero la cuerda no se puede estirar tanto y llegó el momento que el soviético se dio cuenta de que ni podían ni les parecía seguir aguantando durante otra generación más. Es muy interesante fijarse en que el derrumbe se produjo desde dentro. En cierto modo, es algo parecido a una crisis de fe, se pierde la fe en que el hombre podrá forjar, por sí mismo, un mundo feliz. Entonces, los soviéticos empezaron a exigir ahora siquiera un par de bluejeans, -esto es rigurosamente histórico- o lo que fuera, para los hombres de esta generación, y se olvidaron de la felicidad, del comunismo, y de todo lo que desde la generación anterior les habían estado prometiendo. A ambos lados de la cortina de hierro, este estar de vuelta, de las ingenuidades del racionalismo, es característico del siglo $\mathrm{XX}$.

\section{Fundamentalismo democrático}

Según lo han descrito de modo patético, en Europa después de la caída de la Unión Soviética, la democracia, en lugar de emerger triunfante, se desmoronó. Sus lacras, mantenidas piadosamente en silencio -corrupción y abusos de toda especie- a causa del el temor al socialismo real, quedaron ahora en evidencia ${ }^{20}$. Si entonces se prefería el llamado socialismo democrático, por temor al socialismo real, apenas cayó la Unión Soviética, salió a la luz una seguidilla de escándalos, de los que no escapó ni Mitterand, el Presidente de Francia, ni su mujer, ni su hijo, como tampoco el canciller Kohl de Alemania, artífice de la reunificación, ni, en fin, el Primer Ministro de Italia que se suicidó ni otro, Craxi que huyó y está hasta ahora refugiado en Libia. Podría seguir, aunque no vale la pena dedicarse a hacer listas, de escribir, y hablar de personajes comprometedores como ellos. La arremetida se debe a que desapareció el temor a denunciarlos. Ellos dejan ver el rostro de la democracia real. Como hace ver Trías, el derrumbe de la democracia totalitarias, lejos de favorecer a las restantes democracias, según se apresuró a pronosticar Fukuyama en 1989, ha abierto delante de ellas un abismo, ha destapado una verdadera caja de Pandora.

La razón no es difícil de entrever. Junto con el mito del progreso indefinido, ha caído también el mito de la democracia como la más perfecta forma política que sea posible alcanzar a la humanidad Más allá de ella sería imposible pasar. Se comienza a ver sus lacras y la democracia vuelve a ser lo que siempre fue: una más entre las formas de gobierno, y en concreto, una forma de república.

${ }^{19}$ Montesquieu, Charles Secondat, De l'esprit des lois, 11,4 Ginebra, 1748 ahora en sus Oeuvres Completes (ed. A. Masson), 3 vols. París 1950-1955.

${ }^{20}$ Argullol Rafael y Trías Eugenio, El cansancio de Occidente, Barcelona, 1992. 
Esto basta sobre la democracia actual. Los Estados Unidos siguen creyendo en ella y, al menos, esta creencia, les sirve de carta de corso para atacar a los pueblos que les convenga. Practicando el fundamentalismo democrático, que autores estadounidenses como el profesor Charles Elliot han calificado como "el peor espiritu de nuestra democracia...el espiritu bárbaro de arrogancia e imposición de nuestro propio punto de vista"21. Cuando les conviene, atacan a otros países para imponerles por la fuerza la democracia, sobre todo, cuando como, en el caso de Irak, está de por medio el petróleo. Entonces encienden el furor sacro de su entusiasmo democrático que les lleva a destruir países enteros en nombre de lo que llaman su Destino manifiesto ${ }^{22}$. Esa es la situación actual, los que creen en la democracia la utilizan como tapadera para atacar y destruir naciones inocentes. No hacen falta mayores comentarios.

El fundamentalismo democrático es el peor. En nombre de la democracia: hay que obligar a los que no son democráticos, como nosotros, a que lo sean. Y si no, aténgase a las consecuencias. Temprana manifestación de este fundamentalismo democrático fue en el llamado del profesor Wilson, Presidente de los Estados Unidos en 1919, a crear un mundo seguro para la democracia ${ }^{23}$. Por esta vía los Estados Unidos acabaron con el orden político de Europa, lo destruyeron, pero no lograron reemplazarlo. Siempre es más fácil destruir lo que existe que implantar una democracia al gusto cambiante de los estadounidenses.

Después de la caída de la Unión Soviética, en 2001, otro profesor norteamericano Elliot Cohen, dijo a propósito de la guerra contra Saddam en Irak: "Más que una guerra contra el terrorismo, esta es una guerra por extender la democracia". No necesito continuar. Hoy día, el campeón de la democracia son los Estados Unidos, y por eso, como se quejaba un autor europeo, esta superpotencia, quiere establecer un orden del que ella sea el juez y policía, que determina quién es o no suficientemente democrático, quién lo es tibiamente, para aplicarle el correctivo correspondiente y establecer, en dicho país, una democracia, tal como los Estados Unidos determinen. Ante esta situación queda, al menos, un remedio, que es una defensa, que los pueblos civilizados se junten y forjen un orden multipolar, o como se quiera llamar, para mantener a raya a los nuevos bárbaros. Como historiador, no me corresponde ni sabría atisbar el futuro, pero me parece que estos son los términos del problema ${ }^{24}$.

\section{Tres libertades}

Del liberalismo hay menos que decir, tiene una historia más corta. Está más muerto que la democracia y, por lo tanto, merece menos atención. Una cosa es la libertad y otra el liberalismo. Este no se remonta a los griegos, sino al siglo XIX.

Históricamente hablando existen tres libertades ${ }^{25}$, una libertad gregaria, que es casi una contradicción, otra personal que es creadora y otra individual que es conformista.

En muchos pueblos, el hombre está absorbido por el grupo del que forma parte, sea la parentela, la tribu, la aldea, la ciudad. No cabe actuar por sí mismo, al margen de la comunidad a la cual

\footnotetext{
${ }^{21}$ Charles Eliot Norton, profesor de Harvard habla del "surgimiento de un espíritu bárbaro de arrogancia e irracional autoafirmación" y lo califica el "peor espíritu de nuestra democracia". Carta a E. L. Goldkin, Liggio, Leonard, Early Anti-imperialism . Tuchman, Bárbara, The proud Tower, Nueva York-Londres 1966.

${ }^{22}$ Horsman, Reginald, La raza y el destino manifiesto. Orígenes del anglosajonismo racial norteamericano, Cambridge 1981, trad. castellana, México 1985.

${ }^{23}$ Wilson, Woodrow, The World must made safe for democracy, en su Andress to Joint Session of Congress, 2 de abril de 1917. En link, Arthur (editor) the papers of... 58 vols. Princeton, 1966-68, 41525. Cfr. Bainville Jacques, Les dictateurs, París 1935, trad. castellana Santiago 1936.

${ }^{24}$ Bravo Lira, Bernardino “Fiat ius, ne pereat mundus. El Derecho frente a la globalización de la violencia”, en Losano, Mario G. y Muñoz Conde, Francisco (editores) El Derecho ante la globalización y el terrorismo. Valencia, 2004.

${ }^{25}$ Dumont, Louis, Essais sur L'individualisme, Ginebra, 1983. Coleman, Janet, (ed.) The individual in political theory and practice, Nueva York, 1996.
} 
pertenece. Más aún, está al servicio del grupo, no tiene alternativa, porque el núcleo es lo permanente y él mismo lo pasajero. Esto vale, tanto para la polis griega, como para los pueblos y gentes de las más distintas épocas y latitudes, desde el Oriente Antiguo, la China, la India, Africa y la América prehispánica. En todas partes el hombre es un miembro transitorio dentro de un cuerpo permanente.

El gran cambio se produjo con el paso de una libertad gregaria a la libertad personal ${ }^{26}$, debido al Cristianismo. El Cristianismo hizo, por así decir, una trampa, o un giro, al invertir los términos. Mostró que este mundo es pasajero, nada en él es definitivo, por lo que lo calificó de temporal o secular, esto es, perteneciente al más acá, que pasa, y no al más allá que permanece. En cambio, el hombre es lo trascendente. En lugar de estar sumido en este mundo y aplastado por los poderes del aquí y del ahora, puede apelar de este más acá terreno al más allá ultraterreno. Tal es el principio y fundamento de la libertad personal, que trasciende lo temporal y es superior a los poderes de este mundo.

Según esto, el grupo está en función del hombre y no el hombre en función del grupo. Santo Tomás, acertó a condensar la posición del hombre en el mundo en una frase: homo non ordinatur ad communitatem civilem, secundum se totum et tota sud $^{27}$. Quieran o no quieran, esta visión se impone a los poderosos de este mundo. En adelante, no pueden disponer a su amaño de los hombres. Tienen que contar con la posibilidad de que sus exigencias y mandatos sean resistidos, en nombre de otros poderes más altos que el suyo. La situación es completamente distinta a la que existía mientras su poder era el único, como sucede hasta ahora en el mundo musulmán, en China y en muchos pueblos de varios continentes. Si no hay más que un poder único, no cabe otra cosa que someterse al que manda, sea el califa, el príncipe, o el dictador. A la inversa, desde el momento en que se puede invocar a un poder superior al suyo, el gobernante queda advertido de que se le puede oponer resistencia. Entonces, a el mismo, no le queda más remedio que moderarse, inhibirse y calcular hasta que punto le conviene arriesgarse a provocar esa resistencia.

Por cierto, la libertad personal no aparece súbitamente. El espacio propio de ella se asienta en forma gradual, sin espectáculo, pero de manera efectiva, casi irresistible. La visión cristiana del hombre penetra poco a poco, como el riego que transforma las tierras de secano en campos fructíferos. Al respecto, más allá del símil basta pensar cuanto tiempo y esfuerzo costó abrir camino a la convicción de que el matrimonio se constituye por el mutuo consentimiento de los contrayentes y no por decisión de los jefes de la estirpe, familia, tribu. Sabido es que todavía en el siglo XIII las Decretales insisten en que el matrimonio nace de la unión de las voluntades y no de los cuerpos. Hoy día la cuestión no se discute, pero la historia muestra hasta que punto costó que la libertad personal se abriera camino.

\section{Libertad individual}

Con esto podemos pasar a la tercera libertad, de la que nos corresponde ocuparnos en esta exposición: la libertad individual del liberalismo. La libertad personal se basa en la persona, que como recuerdan las Partidas, es la más noble cosa de este mundo. En una palabra, es única e insustituible, en sus actuaciones no puede ser suplantada por otro, ni por un grupo o comunidad. En cambio, la libertad individual se basa en el individuo. Literalmente, individuo -indivisuum en latín- no es sino uno más dentro del género a que se pertenece. Cada animal y cada planta es como un grano de arena, un individuo, pero no una persona. Por el contrario, el hombre, todo hombre, más que simple individuo es una persona.

${ }_{26}^{6}$ Ullmann, Walter, Individumm und Gessellschaft im Mittelalter, Londres, 1967.Gurjewitsch, Aarón J. Das individuum im europäischem Mittelalter,( Moscú, 1972) trad. alemana, Munich, 1978.

${ }^{27}$ Aquinatis, Thomas, Summa Theologiae. 1-2 $2^{\mathrm{a}}, 21$, art. 4,3 
Desde el momento en que, con la Ilustración, al hombre se le considera como individuo, más bien que como persona, se torna posible imaginar que es bueno por naturaleza. No el homo bomini lupus de Hobbes, sino un ser doméstico y benéfico, abierto a los demás. La persona, en cambio, puede ser, o mejor dicho, hacerse buena o mala, según sus actuaciones. En cambio, al individuo se le atribuye de practicar la bondad común a todo su género. En este sentido, se le supone bueno por naturaleza. Fue el famoso Rousseau quien popularizó esta idea. Sin entrar en detalles, vale la pena recordar las circunstancias en que se le ocurrió hacerlo. Fueron por lo demás casuales. Propias de un publicista, más bien que de un pensador.

Había un concurso literario en la Academia de Dijon. Rousseau confidenció a un amigo que quería tratar del ideal ilustrado del progreso indefinido del hombre en el tiempo. Su interlocutor le objetó: "No seas vulgar. Eso lo dice todo el mundo. Mucho más interesante sería sostener, al revés, que el hombre es bueno por naturaleza y la sociedad lo corrompe." Él aceptó la pirueta y tuvo una fortuna inesperada. Todavía hay gente que cree en la bondad natural del hombre. Sin ir más lejos, este es el punto de partida para la idea y el ideal liberal.

La libertad liberal consiste en suprimir las trabas, suprimir las barreras, las reglas, a fin de que el individuo se las maneje a sus anchas. Porque todo lo que haga un hombre bueno, será bueno. En otros términos, cancha, tiro y lado para la actuación del hombre. Lo contrario es frenar el desarrollo individual y con ello, también el de la sociedad.

Sabido es que la palabra liberal procede del castellano. Nació en la época de las Cortes de Cádiz en 1812. Entonces apareció esta nueva acepción de la antigua palabra liberal, distinta de lo que hasta esa época se entendía por tal. El término liberal tiene un origen latino, y alude a una condición interior: la generosidad y apertura a los demás. De ahora en adelante, liberal significó también algo exterior, "supresión de trabas y barreras", es decir, se refirió a una libertad exterior, pues dichas limitaciones son impuestas siempre desde fuera.

¿Cuál fue la clave del liberalismo, y su atractivo para determinados sectores, ansiosos de derribar los obstáculos que coartaran sus actuaciones? Lo que hizo y hace valioso al liberalismo a los ojos de muchos es su imagen idealista, endiosada, del hombre. Si es bueno por naturaleza, todas las libertades son pocas: políticas, religiosas, económicas, sociales, intelectuales. Como dice uno de sus fundadores, Stuart Mill: "La especie humana gana cuando deja actuar al hombre como apetece ${ }^{281 "}$. Según Comte, de este modo, los hombres se harán más ricos, más sabios y más poderosos. En otras palabras, se trata de dejar actuar, el laissez faire de los fisiócratas extendido a la humanidad. De este modo, esa maravilla que es el hombre hará maravillas.

\section{Binomio libertad-seguridad}

Esto equivale a imaginar al hombre sin rayado de la cancha, para emplear una expresión deportiva. Hace lo que quiere y no paga el precio de sus excesos, ni en la salud corporal, ni mental, ni moral, ni social.

Esta visión antropocéntrica de la libertad fue descrita por un autor del siglo pasado, La Tour du Pin, como "la sustitución de la religión del Dios hecho hombre por el hombre hecho Dios ${ }^{29 "}$. Elimina toda referencia superior. En estas condiciones, la libertad fácilmente se autodestruye. Las cosas no son tan simples y el liberalismo tiene problemas. Ya los señaló, por ejemplo, el propio Montesquieu, cuando afirmó que "sólo puede existir la libertad política en un régimen moderado ${ }^{30 "}$. Y ni aun así, pues solo en algunos

\footnotetext{
${ }^{28}$ Mill, Stuart, Essay of Liberty, Londres, 1859.

${ }^{29}$ La Tour du Pin, Vers un ordre social chrétien, París, 1921.

${ }^{30}$ Montesquieu, Charles, (citar un edicion del espritu de las leyes en frances).
} 
regímenes moderados puede subsistir.

Un siglo después, Tocqueville mostró la pendiente que lleva desde el liberalismo hacia el totalitarismo. "El hombre -dice- quiere poder disponer por si mismo, pero por otra parte quiere tener seguridad"1". Esta búsqueda de la seguridad, en todos los planos de la vida, le va doblegando hasta llevarle a la renuncia de su libertad, renuncia que poco a poco, desemboca en el totalitarismo. Porque hay dos totalitarismos, el blando de los Estados Unidos, en principio legal e incruento, y el totalitarismo duro de la Unión Soviética, cruento y violento ${ }^{32}$.

Este problema no ha sido demasiado estudiado. Sin duda es urgente abordarlo. Quien mejor lo expuso fue Jouvenel, un autor francés del siglo pasado. Al término de la Segunda guerra mundial explicó: "La libertad es un bien precioso, como un diamante. Pero eso no interesa a todos "33". Porque una persona que está hambrienta, que no tiene dónde vivir, que carece de vestido, no necesita ni quiere diamantes. Aunque parezca chocante, no necesita libertad, no necesita la libertad exterior del liberalismo. Lo que necesita es con qué comer, con qué vestirse y un lugar donde habitar, pan, techo y abrigo. Según esto, en una amplia simplificación, continúa diciendo Jouvenel, "En toda comunidad hay dos sectores. Uno, que tira

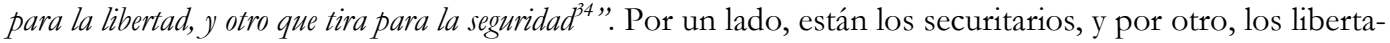
rios. Siempre es más numeroso el necesitado de seguridad.

Esta libertad individual de que estamos hablando no vale para todos por igual. Para los empresarios, la gente con iniciativa, los escritores, los hombres de talento, es muy beneficiosa, como sostenía Stuart Mill. Pero para la gente desposeída y necesitada, que se está muriendo en una casa COPEVA, de esas que se les pasa el agua cuando se llueve, o que no tiene acceso a una escuela básica, obligada a pasar una noche y hacer cola en los hospitales para ser atendida no le sirve de nada una libertad de comprar acciones, moneda extranjera, importar maquinaria, hacer inversiones, viajar a la India, de alojarse en lujosos hoteles o de hacer un crucero por las Islas Vírgenes. Esta gente, que es la mayoría, más que libertad, necesita privilegios, ayudas, ventajas, como hay sobrados ejemplos en el Derecho Indiano. A los necesitados se les atiende y no se les engaña con libertades individuales, iguales para todos, pero inútiles para ellos. Esta es la razón de que en la Postmodernidad el liberalismo se venga abajo sin estrépito, pero con la celeridad del Titanic.

Por último, volvamos al rayado de la cancha, que es como el témpano contra el cual no puede menos que estrellarse el liberalismo. Se dice que Dios perdona siempre. Que los hombres perdonan a menudo. Pero que la naturaleza no perdona nunca. Esto lo sabe desde un drogadicto hasta una persona que abusa de sus fuerzas, más allá de lo que su cuerpo permite. El derrumbe del liberalismo se debe precisamente a esto: a que la naturaleza no perdona. El siglo XX es la época más inhumana de que se tiene noticia, llena de declaraciones de derecho, pero no por eso menos llena de horrores. Existe un Libro negro del comunismo, dirigido por Courtois, que intenta cuantificar las víctimas del marxismo en la Unión Soviética ${ }^{35}$. En lugar de hacerse más ricos, más poderosos y más felices, el hombre se ha hecho peor que un lobo para el hombre, y por toda reacción proliferan organizaciones y gentes que viven espléndidamente, de denunciar a diestra y siniestra violaciones de derechos humanos en salones alfombrados con lámparas de lágrimas y tapete rojo, mientras afuera les aguardan chóferes de uniforme para abrirles la puerta de sus limusinas. Todo esto, por cierto, en nombre de la libertad, la democracia y los derechos humanos. En un plano descarnadamente realista, algunos autores, en cam-

\footnotetext{
31 Tocqueville, nota 14.

32 Reinhard, nota 13.

${ }^{33}$ Jouvenel, Bertrand de, El poder, Ginebra, 1945, trad. castellana, 1946.

${ }_{34}$ Ibíd. nota 33, cap. XVIII Libertad o seguridad.

${ }^{35}$ Courtois, Stéphanie et al, El libro negro del comunismo. Madrid 1998.
} 
bio, hablan del Estado como el mayor asesino de la historia ${ }^{36}$ y se quedan cortos. Otros, como el francés Ternon, hablan derechamente de un "Estado genocida ${ }^{37 " . ~ E ́ l ~ e s ~ t e s t i g o ~ d e ~ l a ~ d e s t r u c c i o ́ n ~ u n ~ p a i ́ s ~}$ como Afganistán, y luego Irak, sin ninguna causa. De todo esto resulta que el hombre no es bueno por naturaleza, y que dejarlo suelto equivale a soltar a una fiera. Esta expresión no es tan terrible como pudiera parecer, pues no hace sino confirmar lo que apuntó hace dos siglos, nada menos que un inglés que hemos citado, Hobbes, quién califica al hombre como lobo para el hombre.

Efectivamente, eso se ha visto. Si algo ha demostrado el siglo XX es que los peores sufrimientos de la humanidad han sido causados por los propios hombres. A diferencia de los salvajes, los civilizados del siglo XX, se han servido de una técnica sin par para exterminar pueblos enteros ${ }^{38}$. Habría que tener un poco más de cautela frente a la admiración incondicionada de la técnica. A mediados del siglo, cuando aún no se habían perpetrado todos los horrores, un autor francés, Henri de Lubac, dijo: "el hombre puede muy bien forjar un mundo sin Dios, pero no puede evitar que sea contra el hombre"39. Ese es el problema de fondo de una democracia, en donde todo se puede aprobar mediante los votos y la elección de una mayoría. O en el liberalismo, donde cualquier cosa se puede hacer, siempre que sea por propia iniciativa. O sea, el hundimiento de la democracia y el hundimiento del liberalismo no fueron de ningún modo casuales. Si uno obra de determinada manera, si uno quiebra el orden, de la salud corporal, moral o del conocimiento, tiene que pagar las consecuencias. Esto es tarde o temprano ineludible. Todo lo que he dicho es de sobra conocido y casi se diría vulgar. No he desenterrado a ningún autor ignoto. Todo esto se puede sintetizar en la expresión de Lyotard, autor francés de este siglo:

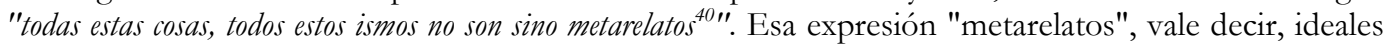
vacíos, por los que se jugaron los hombres, hasta morir a veces por ellas, no podían realizarse. Eran espejismos. El hombre no puede construir el mundo, ni mucho menos. Me parece que la afirmación de Lyotard es un tanto excesiva, en cambio, encuentro muy exacto lo que dice Vattimo: "Nada hay nada más insensato que creer que el hombre, una mota de polvo en el universo, va a poder cambiar algo del mismo ${ }^{41 "}$.

En suma, la idea ilustrada de que el hombre estaba llamado a rehacer el mundo de acuerdo a la razón humana, es una ilusión, tan atractiva como imposible. El hombre podrá mejorar esto o aquello, pero rehacer el mundo, eso no está en su mano. Antes bien, el mundo se venga, cuando uno intenta rehacerlo. Por eso, termino diciendo que si uno mira los hechos, o para emplear la expresión de Portales, que aquí viene muy bien, "los porfiados hechos", tendrá que sacar la conclusión de que tratar de casar la democracia con el liberalismo, fue un juego teórico decimonónico, de la Modernidad. En la época postmoderna tales intentos perdieron todo sentido. La razón es aplastante. Puesto que ambos se derrumbaron, la democracia y el liberalismo, ya no hay nada que casar. Intentarlo ahora, sería como tratar de armar un centauro, con la parte superior de un hombre y las patas de un caballo. Lo peor que podría ocurrirle a alguien, si se llega a meter entre las patas del centauro, es terminar maltrecho. Más allá no se va a llegar. Pienso que, en cambio, hay que poner la imaginación y la iniciativa en buscar soluciones concretas para problemas concretos. En otras palabras, dejarnos de soñar en soluciones, como las ideologías del siglo XX, que sirvan para todos los problemas y sean la clave del siglo actual. Volver a eso, equivaldría a reemplazar un metarelato por otro, es decir, no haber olvidado nada ni aprendido nada.

\footnotetext{
${ }^{36}$ Johnson, Paul, Tiempos modernos (1983), Buenos Aires 1988.

${ }_{37}$ Ternon Yves, L'Etat criminel. Les génocides du XX é siécle, París 1994.

${ }^{38}$ Zun Felde, Alberto El ocaso de la democracia, Santiago, 1989.

${ }^{39}$ Lubac, Henri de, El drama del bumanismo ateo,(1944), Madrid 1955.

${ }^{40}$ Lyotard, nota 2.

${ }^{41}$ Vattimo, nota 3.
} 